\title{
As Soluções Traçadas no Ordenamento Jurídico Português para o Problema do Lucro da Intervenção
}

\author{
Portuguese Legal System Solutions for the Profit of Intervention Problem
}

\author{
Sabrina Jiukoski da Silva ${ }^{1}$ \\ Rafael Peteffi da Silva ${ }^{1}$ \\ ${ }^{1}$ Universidade Federal de Santa Catarina, Florianópolis, SC, Brasil
}

\begin{abstract}
Resumo: A problemática que envolve a aquisição de lucros a partir da intervenção nos direitos subjetivos alheios vem recebendo, nos últimos anos, especial atenção da doutrina nacional. Assim, visando de contribuir com possíveis soluções para o ordenamento jurídico brasileiro, objetiva-se, no presente artigo, retratar outra realidade jurídica, o ordenamento jurídico português, que há quase quatro décadas vem debatendo a problemática. Para tanto, utiliza-se do método dedutivo com consulta de fontes bibliográficas primárias e secundárias. Conclui-se, ao final, que o lucro da intervenção é reconhecido pela doutrina como um produto do enriquecimento sem causa em Portugal, mas existe divergência doutrinária sobre a possibilidade de sua restituição, e o legislador no âmbito dos direitos imateriais o inseriu como hipótese no cálculo das indenizações.
\end{abstract}

Palavras-chaves: Lucro da Intervenção. Enriquecimento sem Causa. Responsabilidade Civil.
Abstract: The problem that involves interventions in the subjective rights, especially the profit of intervention, has been receiving special attention of the brazilian doctrine. Thus, in order to contribute to possible solutions to the Brazilian legal system, this article aims to portray another legal system, the portuguese legal system, which for almost four decades has been debating the problem, providing a deeper understanding to the issue. Therefore, the deductive method is the research methodology used throughout the article. It is possible to conclude that Portuguese legal scholars have largely stand for the categorization of the profit of intervention within the scope of the unjustified enrichment, but they diverge on the possibility of its restitution, and specific laws on immaterial rights have inserted the profit of intervention as a way for calculating damages.

Keywords: Profit of Intervention. Unjustified Enrichment. Civil Liability.

Recebido em: 04/07/2019

Revisado em: 02/10/2020

Aprovado em: 27/10/2020 


\section{Introdução}

Entre as preocupações da civilística nacional destacam-se, nos últimos anos, as situações nas quais um determinado agente aufere lucros a partir da exploração ou aproveitamento, intencional ou não, de forma não autorizada, de bens ou direitos alheios (KONDER, 2017, p. 233). É a empresa que usa sem autorização a imagem ou o nome de pessoa pública, seja um ator, um compositor ou um atleta famoso, para comercialização de um determinado produto; o editor que publica uma obra literária sem o consentimento do autor; ou, ainda, o jóquei que usa o cavalo de corrida de outrem para ganhar uma premiação.

Esses lucros apurados a partir do ato de intervenção nos direitos subjetivos $^{1}$ alheios vêm sendo denominados, na literatura nacional, de lucro da intervenção. A expressão busca denominar os ganhos apurados pelo incremento no valor presente do patrimônio do agente interventor ${ }^{2}$, ganhos esses que estão além da concepção clássica de enriquecimento, que compreende os valores que normalmente seriam contratados pelas partes para utilização ou consumo daquele bem ou direito de outrem. Para exemplificar, se um determinado sujeito invade o terreno alheio para a colocação e a comercialização de um outdoor, este poderá obter um lucro a partir da exploração comercial, resultado líquido que se denomina de lucro da intervenção, porém, ao mesmo tempo, acabará poupando os alugueres do terreno, e essa economia é o que se trata por enriquecimento na sua concepção clássica nacional.

\footnotetext{
${ }^{1} \mathrm{Na}$ definição de Miguel Reale, um direito subjetivo compreende a "[...] possiblidade de exigir-se, de maneira garantida, aquilo que as normas de direito atribuem a alguém como próprio" (REALE, 2005, p. 260).

${ }^{2} \mathrm{O}$ conceito de lucro é trabalhado, à luz das Ciências Contábeis e das Ciências Econômicas, como a "[...] recompensa e a motivação para a instalação e continuidade de um empreendimento na sociedade capitalista" (FUJI, 2004, p. 76). Essa anotação tornase importante, pois, o termo lucro da intervenção, será empregado como concebido pela doutrina nacional e, aparentemente, aceito pela jurisprudência pátria, ou seja, como os lucros apurados pelo incremento no valor presente do patrimônio do agente interventor. Ao contrário do direito português, que classifica todas as vantagens econômicas que determinado agente recebe a partir de uma intervenção, sem autorização, nos direitos alheios, em um sentido amplo, como lucro da intervenção.
} 
O relativo ineditismo da temática traz consigo, contudo, a dificuldade de enquadrá-la em algum dos institutos de Direito Civil reconhecidos na leitura do ordenamento jurídico pátrio, bem como de quantificá-la. Atualmente, é possível identificar recentes, mas valiosas reflexões sobre a temática, que, em essência, defendem que o titular do direito subjetivo violado tem a pretensão de exigir os lucros que o agente interventor obteve a partir do uso, consumo, fruição ou alienação dos direitos ou bens que lhe pertencem, recaindo sobre o tema a seguinte indagação: com qual fundamento e em que medida o lucro da intervenção deve ser transferido para o patrimônio do titular do direito violado.

Nesse contexto, o presente estudo objetiva, a partir do raciocínio dedutivo, introduzir o problema do lucro da intervenção segundo o ordenamento jurídico português, em que a doutrina e a jurisprudência há muito identificaram a complexidade do tema, pois, acredita-se que uma análise do direito estrangeiro servirá de importante lente de inspiração para, resguardadas as particularidades do ordenamento jurídico pátrio, delinear em momento oportuno o enquadramento e a quantificação do lucro da intervenção no cenário brasileiro. Não é objeto do presente estudo, assim, apresentar uma solução aplicável aos casos de intervenção para o direito brasileiro, ficando-o restrito à perspectiva geral do direito português, considerando o enquadramento e a possibilidade de devolução destes lucros.

Como corolário lógico, o desenvolvimento do presente estudo está dividido em três seções. A primeira que demonstrará as linhas gerais do reconhecimento do lucro da intervenção no direito português. A segunda seção cuidará do tratamento conferido à temática neste ordenamento jurídico. A terceira seção alertará para as soluções trazidas pela legislação portuguesa aos casos de intervenção nos direitos de propriedade intelectual. Por último, serão tecidas as considerações finais e conclusas da presente pesquisa.

\section{A Descoberta do Lucro da Intervenção no Direito Português}

A primeira obra que tratou sobre o tema do lucro da intervenção no direito português, despertando, inclusive, a curiosidade dos demais dou- 
trinadores civilistas, foi desenvolvida pelo catedrático Francisco Manuel Pereira Coelho nos idos dos anos 1970 (PEREIRA COELHO, 1970) 3 .

O interesse teórico do doutrinador português, na época, estava alinhado à tentativa de sistematização geral da problemática que envolve o lucro da intervenção, buscando situar o seu lugar a partir de uma reflexão sobre o enriquecimento e o dano, dado que o tema se prende, nas suas raízes, às noções mais essenciais dos institutos do enriquecimento sem causa e da responsabilidade civil. Além disso, objetivava delinear a possibilidade de transferir esses valores auferidos pelo interventor ao titular do direito e até que ponto esta transferência seria possível segundo as linhas do ordenamento jurídico português ${ }^{4}$.

As reflexões traçadas, portanto, partiram de dois questionamentos-chave: "A quem pertence o lucro por intervenção?" e "Dum modo geral, que dirão o interventor e o titular do direito?" (PEREIRA COELHO, 1970, p. 17).

Segundo Pereira Coelho (1970, p. 17-19), o titular do direito violado defenderia que o lucro da intervenção é seu, pois produzido a partir de seus bens, e o exigiria como quem reivindica o que lhe pertence. A tese sustentaria, em primeiro, que a iniciativa do interventor não merece qualquer proteção legal, dado ao exercício ilegítimo sobre bens alheios, sendo que a obrigação de restituir os lucros auferidos seria uma sanção adequada ao procedimento de quem assim abusivamente interveio na sua esfera jurídica. Em segundo, defenderia que permitir ao interventor fazer seu o

\footnotetext{
${ }^{3}$ A obra recebeu especial atenção da doutrina nacional quanto ao enquadramento dogmático dessa vantagem econômica no direito brasileiro, sobretudo na tese de doutoramento de Sérgio Savi, que faz referência, inclusive, a importância do estudo de Pereira Coelho em Portugal (SAVI, 2012, p. 7-8).

${ }^{4}$ Pereira Coelho (1970, p. 14) coloca, analisando o direito estrangeiro, que o estudo do lucro da intervenção está essencialmente vinculado ao seu enquadramento em um dos dois institutos, pois para alguns doutrinadores trata-se de um problema de enriquecimento sem causa (doutrinadores alemães) para outros de responsabilidade civil (doutrinadores italianos). No mesmo sentido, anos depois, Viera Gomes, afirmou que a restituição do lucro da intervenção situa-se numa espécie de "terra-de-ninguém", entre os institutos da responsabilidade civil e do enriquecimento sem causa, sendo sua localização condicionada, necessariamente, a compreensão inicial de cada instituto e dos seus respectivos pressupostos e funções (VIEIRA GOMES, 1998, p. 792).
} 
lucro obtido seria estimulá-lo a intervir nos direitos alheios, sem falar que a obrigação de restituir não prejudicaria o interventor, pois este só teria que restituir o que está a mais no seu patrimônio e que obteve a partir de sua ação ilícita.

O agente interventor, por outro lado, defenderia que o lucro é fruto de sua atividade e iniciativa, porventura do emprego do seu capital ou da sua força de trabalho, do modo como soube negociar ou aplicar os bens ou direitos alheios. Estes últimos, ainda, não seriam a única causa do lucro, mas concausa e, de todas, a menos eficiente. Dessa forma, defenderia que seria injusto obriga-lo a restituir o lucro da intervenção ao titular do direito, pois seria premiar a inatividade deste e esta transferência constituiria uma verdadeira pena privada, que a legislação não lhe deverá impor (PEREIRA COELHO, 1970, p. 19-20).

A partir deste trabalho inicial, outros doutrinadores, como Diego José Paredes Leite de Campos (1974), Rui de Alarcão (1983), João de Matos Antunes Varela (1994), Mário Júlio de Almeida Costa (1994)5 , Júlio Manuel Viera Gomes (1998) e Luís Manuel de Menezes Leitão (2005), se dedicaram ao estudo do lucro da intervenção.

As construções da civilística portuguesa sobre o tema, assim como as reflexões de Pereira Coelho, sofreram uma forte influência germânica. Isso porque as raízes da pretensão ao lucro da intervenção têm suas origens no direito alemão, através das concepções, iniciadas, pelo doutrinador Fritz Schulz sobre o instituto do enriquecimento sem causa.

O legislador alemão ao consagrar uma cláusula geral de vedação ao enriquecimento sem causa no $\S 812$ do $\mathrm{BGB}^{6}$ optou por utilizar a expres-

\footnotetext{
${ }^{5}$ Esses dois doutrinadores, Antunes Varela e Almeida Costa, publicaram suas obras anteriormente tratando sobre o tema, mas não se obteve acesso aos primeiros exemplares, apenas aos exemplares de 2005 e 2009.

${ }^{6}$ A sigla utilizada diz respeito ao Bürgerliches Gesetzbuch, o Código Civil alemão de 1900. O artigo 812, por sua vez, tem a seguinte redação: $§ 812$ : “(1) Wer durch die Leistung eines anderen oder in sonstiger Weise auf dessen Kosten etwas ohne rechtlichen Grund erlangt, ist ihm zur Herausgabe verpflichtet. Diese erpflichtung besteht auch dann, wenn der rechtliche Grund später wegfällt oder der mit einer Leistung nach dem Inhalt des Rechtsgeschäfts bezweckte Erfolg nicht eintritt. Tradução livre: Quem pela prestação de outra pessoa, ou por qualquer outro modo às suas custas, obter para si alguma coisa,
} 
são auf dessen Kosten (à sua custa) e, a partir dessa redação, considerando uma interpretação alargada, Schulz passou a defender que nas bases do instituto não está o princípio da equidade ou a ideia de deslocamento patrimonial ${ }^{7}$, mas sim a antijuridicidade ou a ilicitude ${ }^{8}$ da conduta contrária ao ordenamento jurídico. Para Schulz, ninguém deve obter uma vantagem patrimonial através de uma intervenção ilícita num direito subjetivo alheio, sendo necessária a devolução, ao titular do direito, de tudo aquilo que o interventor adquiriu ilicitamente, tanto o enriquecimento em sua concepção clássica quanto o lucro da intervenção (MENEZES LEITÃO, 2005, p. 392).

A intervenção nos direitos subjetivos alheios daria ao titular do direito a pretensão de restituir o que Schulz denominou de eingriffserwerb, ou seja, de lucro da intervenção ${ }^{9}$, abrindo caminhos para o surgimento da doutrina da Eingriffskondiktion (condictio por intervenção), cuja descoberta apresentou uma reformulação dogmática do instituto do enriquecimento sem causa na Alemanha (MENEZES LEITÃO, 2005, p. 349).

Todavia, a teoria desenvolvida pelo doutrinador alemão Fritz Schulz restou, ao longo dos anos, não mais defendida no ordenamento jurídico

sem fundamento jurídico, estará obrigado, para com este, à restituição. Esta obrigação existe ainda quando o fundamento jurídico mais tarde vier a faltar, ou quando, com uma prestação, não se realizar o resultado visado de acordo com o conteúdo do negócio.

${ }^{7}$ A ideia de descolamento patrimonial tem suas raízes na doutrina alemã pandectística, iniciada com os estudos de Savigny, que, antes mesmo do Código Civil alemão, buscava dar fundamento e consolidar um instituto do enriquecimento sem causa (MENEZES LEITÃO, 2005, p. 339-342).

${ }^{8}$ Rafael Peteffi da Silva (2019, p. 449) ensina que o termo antijuridicidade é fruto do desenvolvimento observado na doutrina penal alemã, mas desde as primeiras traduções do instituto feitas por países de origem latina, como o português e o espanhol, passaram a considerar, nesses países, os termos ilicitude e antijuridicidade muitas vezes por sinônimos e outras tantas vezes utilizados para marcar diferenças conceituais. No decorrer do presente estudo, diante da utilização das bases doutrinárias essencialmente portuguesas e espanholas, os termos serão empregados como sinônimos.

${ }^{9} \mathrm{Na}$ doutrina alemã a expressão eingriffserwerb é utilizada para denominar qualquer vantagem que foi adquirida pelo agente interventor, compreendendo assim tanto o enriquecimento em sua concepção clássica quanto o que a doutrina nacional, nestes últimos anos, denomina de lucro da intervenção. Os lucros da intervenção, para os alemães, traduzem-se como todo o enriquecimento derivado do ato de intervenção. 
alemão, sendo considerada um dos pontos de partida para a construção do enriquecimento sem causa. Aos poucos, consequentemente, surgiram novas teorias para dar fundamento ao instituto.

A moderna doutrina dualista, consagrada atualmente, possui sua origem nos trabalhos desenvolvidos por Walter Wilburg e seguidos, em certa medida, por Ernst Von Caemmerer. A essência doutrinária das duas teses reside na divisão do $\S 812$ do $\mathrm{BGB}$, dos próprios fundamentos do enriquecimento sem causa, em duas hipóteses: a primeira relativa às condictiones com base numa prestação (durch die Leistung eines anderen) ${ }^{10}$ e, a segunda, às condictiones não baseadas numa prestação (auf dessen Kosten in sonstiger Weise), na qual se atribui papel predominante à Eingriffskondiktion (MENEZES LEITÃO, 2005, p. 399-400).

Segundo Wilburg, quando o enriquecimento não ocorre por meio de uma prestação, o que estaria em jogo seria a tutela do direito subjetivo alheio à custa do qual a vantagem econômica se verificou. A construção

\footnotetext{
${ }^{10}$ Para Wilburg, as condictiones por prestação estão baseadas num ato voluntário e estabelecem uma forma de impugnação jurídico-negocial, sendo a base da impugnação sobretudo o erro do prestante sobre a causa jurídica da sua prestação. Esta classificação diz respeito, assim, às situações em que alguém efetua uma prestação a outrem, mas se verifica uma ausência de causa jurídica para que possa ocorrer, por parte desse, a recepção dessa prestação, o que estaria, por exemplo, para Menezes Leitão, abarcado no Código Civil de 2002, nas disposições sobre o pagamento do indevido, que corresponde à tradicional condictio indebiti, a qual trata separadamente do enriquecimento sem causa, nos arts. 876 e ss., e ainda nas referências à condictio ob turpem vel iniustam causa, no artigo 883 - que exclui a restituição e determina a atribuição do recebido a estabelecimento de beneficência - e a condictio ob causam finitam, no artigo 885. O enriquecimento resultante de despesas efetuadas por outrem (Aufwendungskondiktion) estaria regulado nas despesas para produção de frutos (artigo 1.214, parágrafo único e artigo 1.216); na restituição das benfeitorias necessárias e úteis ao possuidor (artigo 1.219 e ss.); e na confusão, comissão ou adjunção (artigo 1.272 e ss.). Por fim, o enriquecimento por desconsideração de patrimônio, que trata da possibilidade de ultrapassar o patrimônio de alguém com quem o empobrecido entra em relação e demandar diretamente, com base no enriquecimento sem causa, um terceiro que obteve a sua aquisição, não a partir do empobrecido, mas a partir do patrimônio interposto, estaria disposto no parágrafo único do artigo 879, no qual se prevê a restituição pelo adquirente por título gratuito, ou pelo adquirente de má-fé por título oneroso, do imóvel que o enriquecido alienou (MENEZES LEITÃO, 2004, p. 28-31). Deixa-se, porém, de analisar as condictiones por prestação, passando ao estudo da Eingriffskondiktion, dado à temática do presente estudo.
} 
dogmática de sua teoria da condictio por intervenção apoia-se no direito de propriedade ${ }^{11}$ e não mais na antijuricidade da conduta. Para o autor, a Eingriffskondiktion tem como base a concepção de conteúdo de destinação (Zuweisungsgehalt), que reserva ao titular do direito violado, além da cessação da intromissão, da remoção de seus efeitos e de eventuais indenizações pelos danos causados, o reconhecimento da pretensão às vantagens econômicas auferidas pelo interventor, ou seja, tanto o enriquecimento quanto o lucro da intervenção (BASOZABAL ARRUE, 1998, p. 69).

A esse respeito, Menezes Leitão explica que o fim econômico da propriedade ultrapassa o poder direto e imediato sobre a coisa para Wilburg. A qualificação da pretensão de enriquecimento é, portanto, uma pretensão continuada da atuação jurídica relativa a todos os bens que caem no âmbito da destinação dos direitos. O pressuposto dessa pretensão é, em qualquer caso, a destinação de um bem jurídico à utilidade alheia, tendo ela por conteúdo a restituição da utilidade assim obtida (MENEZES LEITÃO, 2005, p. 403-404).

$\mathrm{O}$ interventor será obrigado a restituir ao titular do direito àquela parte das vantagens auferidas que mantenham ligação econômica e direta com o direito violado. Wilburg considera que é excessivo impor a restituição de todas as vantagens obtidas pela intervenção como defende Schulz. O ideal seria a realização de uma ponderação dos fatores que contribuíram para a obtenção dessas vantagens, atendendo, também, a ideia de que no caso do lucro da intervenção existe uma proporcionalidade do lucro em atenção à importância relativa de cada fator no processo de sua obten-

11 Lembra Vieira Gomes que Walter Wilburg “[...] não restringe a pretensão de enriquecimento às situações em que o direito de propriedade está em jogo, antes, reconhece que tal pretensão pode ter igualmente lugar, quando se trate de direitos aparentados à propriedade sobre bens imateriais que reservam a utilização de uma criação espiritual ao seu criador, como é o caso da patente, do direito do autor e, em certos casos, do direito das marcas. É até original a posição que perfilha relativamente a certos bens componentes da personalidade, mas que, na sociedade contemporânea, assumem cada vez mais um significado patrimonial, como sejam: o nome, a imagem e a própria força de trabalho" (VIEIRA GOMES, 1998, p. 188). 
ção e, consequentemente, garantindo uma adequada remuneração do fator alheio empregado (VIEIRA GOMES, 1998, p. 190-191).

As ideias de Wilburg vieram a ser desenvolvidas, posteriormente, por Von Caemmerer que igualmente parte do conceito central de conteúdo de destinação, com fulcro no direito de propriedade, na construção de sua doutrina da Eingriffskondiktion.

Von Caemmerer (1966, p. 580-581) entende que ao proprietário da coisa pertence usá-la, consumi-la, vende-la, aproveitá-la ou explorá-la, e se alguém usa um direito alheio, obtendo uma vantagem, deve segundo o conteúdo de destinação devolver ao proprietário, pois, somente a ele pertence esse direito. Todavia, para o autor, a intervenção não pode fundamentar uma pretensão que vá além da destinação de um direito subjetivo, não sendo assim objeto da pretensão restituitória os lucros da intervenção, mas sim equilibrar a ordem jurídica com a restituição do valor do desfrute do bem violado (BASOZABAL ARRUE, 1998, p. 71).

O interventor deverá, para Von Caemmerer, restituir o montante que normalmente pagaria para usar, consumir ou dispor do bem objeto de intervenção, nem mais nem menos. Qualquer que seja o saldo existente a maior no patrimônio do interventor a ele pertence (PEREIRA COELHO, 1970, p. 70). Em outras palavras, apenas é objeto do instituto do enriquecimento sem causa a restituição do enriquecimento em sua concepção clássica, não sendo possível restituir os lucros da intervenção.

$\mathrm{Na}$ esteira de Wilburg e Von Caemmerer, a opinião largamente dominante na doutrina germânica, atualmente, é aquela que nega a unidade do instituto do enriquecimento sem causa, acolhendo a teoria dualista ${ }^{12} \mathrm{e}$, como corolário, a condictio por intervenção ganha significativo espaço no âmbito do enriquecimento sem causa. No entanto, a grande divergência está

\footnotetext{
${ }^{12}$ Nesse sentido, ver Vieira Gomes (1998, p. 197), Menezes Leitão (2005, p. 408-411) e Antunes Varela (2005, p. 491-493). Ainda, a jurisprudência alemã aceitou a doutrina da divisão do instituto nos anos de 1960, no caso Elektrogeräte-Fall (ent. 31/10/1963, em BGHZ 40, p. 272-282), em que, aplicando o conceito de prestação veio a defender que esta consistiria no consciente e finalisticamente orientado aumento de um patrimônio alheio, provocando, para Menezes Leitão (2005, p. 411), uma reviravolta na jurisprudência alemã.
} 
na possibilidade de restituição dos lucros da intervenção, que, como analisado, só seriam restituídos segundo a concepção defendida por Wilburg.

A gênese histórica do enriquecimento sem causa no direito alemão, que trata o lucro da intervenção como um produto da condictio por intervenção, ganhou a atenção da civilística portuguesa que, aos poucos, foram introduzindo os pensamentos doutrinários germânicos na construção do instituto em Portugal e se posicionando, nesse contexto, sobre a possibilidade, ou não, de restituição dos lucros da intervenção, como se investigará na próxima seção.

\section{O Instituto do Enriquecimento sem Causa e (im)Possibilidade de Restituição do Lucro da Intervenção no Direito Português}

O instituto do enriquecimento sem causa no ordenamento português é fruto de uma lenta construção doutrinária, dado que a primeira codificação civil portuguesa, o conhecido Código de Seabra de 1867, não consagrou o instituto diante da grande influência napoleônica da época ${ }^{13}$, o que levou, também, à recepção tardia do instituto pelos tribunais portugueses, que praticamente pareciam desconhecê-lo, pautando sua análise em um princípio de equidade (MENEZES LEITÃO, 2005, p. 322).

A positivação de uma cláusula de vedação ao enriquecimento sem causa ocorreu, portanto, somente no Código Civil de 1966. O anteprojeto da codificação, idealizado por Vaz Serra, demonstrava a recente abertura doutrinal para às raízes do instituto segundo o direito germânico, consagrando uma cláusula geral à semelhança do BGB. Contudo, somente

\footnotetext{
${ }^{13}$ Em França, diante da ausência de uma cláusula geral de vedação ao enriquecimento sem causa no Código Napoleônico, a doutrina e a Corte de Cassação francesa, recusavam-se a admitir o enriquecimento sem causa como gerador de obrigações. $O$ início da consagração do instituto em França deu-se somente após o abandono da concepção exegética, no período de 1870 a 1892, com a adesão da doutrina de Aubry e Rau. Todavia, somente em 1892, a partir do célebre arrêt Boudier que a Corte de Cassação francesa reconheceu, de fato, a existência de uma ação autônoma de restituição, fundada no enriquecimento sem causa, bem como introduziu de forma alargada o instituto como princípio geral no direito francês, baseado na equidade (MENEZES LEITÃO, 2005, p. 293; LEITE DE CAMPOS, 1974, p. 151-157; VIEIRA GOMES, 1998, p. 151).
} 
após as revisões de Antunes Varela que se adotou a moderna doutrina da divisão do instituto, reconhecendo, no direito português, a categoria da condictio por prestação, o que para os portugueses resume-se em enriquecimento por prestação e, outra, aquela não baseada em uma prestação, cuja hipótese de maior relevância diz respeito à condictio por intervenção ou enriquecimento por intervenção (MENEZES LEITÃO, 2005, p. 380$383)^{14}$.

O instituto é composto de diferentes categorias ${ }^{15}$ à luz do direito alemão, porém, devido aos resquícios da influência francesa, a versão final da codificação regulou a subsidiariedade da restituição por enriquecimento sem causa ${ }^{16}$. Uma vez verificada a intervenção nos direitos subjetivos

${ }^{14}$ A cláusula geral está consagrada no artigo $473^{\circ}$ que dispõe: (I) "aquele que, sem
causa justificativa, enriquecer à custa de outrem é obrigado a restituir aquilo com que
injustamente se locupletou" e (II) "a obrigação de restituir, por enriquecimento sem
causa, tem de modo especial por objecto o que for indevidamente recebido, ou o que for
recebido por virtude de uma causa que deixou de existir ou em vista de um efeito que não
se verificou". ${ }^{15}$ Em Portugal, o instituto está dividido em quatro classificações: enriquecimento por intervenção (condictio por intervenção), enriquecimento por prestação (condictio por prestação), enriquecimento resultante de despesas efetuadas por outrem (condictio por dispêndios) e enriquecimento por desconsideração do patrimônio do alienante em caso de transmissão de bens para terceiros (MENEZES LEITÃO, 2005, p. 954-958). No entanto, o presente trabalho por limitar-se ao estudo do lucro da intervenção, dará atenção à condictio por intervenção.

16 Em França, "o arrêt Boudier originou que a jurisprudência francesa aplicasse amplamente a action de in rem verso, por vezes em detrimento de outros institutos jurídicos que melhor regulariam o caso em questão. Essa tendência inicial veio, no entanto, a ser extremamente criticada pelo facto de consagrar o princípio da proibição do enriquecimento em termos tão vagos e imprecisos que colocariam em causa a segurança jurídica. Em consequência dessa reação, a jurisprudência veio posteriormente a precisas nas decisões da Cassation de 12.5.1914 (arrêt Clayette) e 2.3.1915 (arrêt Briauhant) os pressupostos da acção estabelecendo, na sequência da doutrina de Aubry e Rau, duas exigências complementares: o enriquecimento deveria ter sido obtido sem causa legítima e o empobrecido não poderia ter à sua disposição nenhuma outra acção [...]" (MENEZES LEITÃO, 2005, p. 294). Na Alemanha, a doutrina largamente dominante entende que as normas do enriquecimento podem concorrer com outras normas, excluindo-se somente nos casos dos $\$ 987$ e ss. (regras quando ao possuidor) e $\$ 346$ e ss. (restituição fundada em rescisão de contrato) (LEITE DE CAMPOS, 1974, p. 109 e ss.). Em Portugal, o art. $474^{\circ}$ dispõe: "Não há lugar à restituição por enriquecimento, quando a lei facultar ao 
alheios, o titular do direito só poderá valer-se da classificação condictio por intervenção, se verificada a existência de uma situação de fato não regulada por qualquer outra norma, integrando ainda os pressupostos do instituto do enriquecimento sem causa (LEITE DE CAMPOS, 1974, p. $327)^{17}$.

Antunes Varela (2005, p. 482 e ss.), ainda, ensina que são três os pressupostos para configuração da pretensão de restituir: o enriquecimento, à custa de outrem e a inexistência de causa justificatidora. O enriquecimento traduz-se na obtenção de uma vantagem de carácter patrimonial, seja qual for a forma que essa vantagem se caracteriza: aumento do ativo patrimonial, diminuição do passivo, poupança de despesas. O segundo requisito, à custa de outrem, diz respeito ao fato de a vantagem foi alcançada a partir do patrimônio de outrem. Abrange tanto a ideia de deslocamento patrimonial - de que o valor entrou no patrimônio do enriquecido é o mesmo que sai do patrimônio do empobrecido -, quanto à intervenção em direitos subjetivos alheios - que a vantagem do beneficiado ocorreu à custa do dono da coisa. A noção de ausência de causa do enriquecimento, por fim, varia consoante a natureza jurídica do ato que lhe serve de fonte. Se for uma obrigação negocial, a causa consiste no fim típico do negócio. Se não houve causa jurídica capaz de justificar a vantagem, esta será sem causa e, portanto, caracterizado o dever de restituir.

O problema que envolve a intervenção nos direitos alheios, com a possibilidade de restituição das vantagens econômicas através das linhas gerais da condictio por intervenção, colocou-se pela primeira vez no Superior Tribunal de Justiça português no âmbito do direito de propriedade, antes da entrada em vigor do Código Civil de 1966, com o seguinte caso:

empobrecido outro meio de ser indemnizado ou restituído, negar o direito à restituição ou atribuir outros efeitos ao enriquecimento".

${ }^{17}$ A lei nega o direito à restituição nos casos de prescrição, usucapião, prestação de alimentos provisórios e no caso dos frutos naturais e civis percebidos pelo possuidor de boa-fé (art. 1270), bem como atribui, outros efeitos ao enriquecimento, quanto às benfeitorias úteis que possam ser levantadas sem detrimento da coisa (art. 1273), quanto à especificação do regime de acessão (art. 1337), quanto ao regime da gestão de negócios (art. 472) (ANTUNES VARELA, 2005, p. 500; LEITE DE CAMPOS, 1974, p. 326). 
O dono de um terreno arenoso plantado de amieiros, na margem do rio Dão, verificou que os donos do prédio vizinho tinham cortado 205 pés de amieiro e retirado daquele terreno 500 camionetas de areia, que posteriormente venderam, pelo que lhes intentou uma ação de indenização com fundamento na responsabilidade civil (art. 2361 do Código Civil de 1867). Os réus defenderam-se alegando, entre outras coisas, que, por força da ação do rio, o terreno ribeirinho se encontrava a receber de novo a quantidade de areia que the tinha sido retida. O STJ entendeu que esta situação impedia a atribuição de indenização pela extração de areia do terreno, nos ternos do art. 2364 do Código Civil de 1867, pelo que julgou ação apenas procedente quanto à indenização pelo corte dos amieiros, considerando, no entanto, que a restituição do enriquecimento dos réus à custa dos autores poderia ser exigida numa outra ação, em que se invocasse essa causa de pedir. (Cfr. Ac. STJ 3/4/1964 em BMJ 136 (Maio 1964), p. 317-322; RLJ 97 (1964-1965), p. 331-334 apud MENEZES LEITÃO, 2005, p. 691)

Apesar de, nesse acórdão, a referência à condictio por intervenção não passar de um obter dictum, Menezes Leitão (2005, p. 691) ensina que foi a partir desse julgado que a doutrina portuguesa começou a se interessar, efetivamente, pelo estudo das hipóteses de enriquecimento resultantes de uma intervenção em bens ou direitos alheios.

As anotações ao acordão, realizadas por Vaz Serra, foram no sentido de que teria lugar a ação de enriquecimento sem causa, independentemente da existência de um prejuízo efetivo, pois, ocorrendo a utilização de um bem alheio, embora inexistente a deslocação patrimonial, não seria razoável que o interventor guardasse para si o valor dessa utilização, devendo, segundo a teoria do conteúdo da destinação, restituir as vantagens econômicas. Essa solução, assim, foi seguida por grande parte da doutrina (MENEZES LEITÃO, 2005, p. 692).

Conforme Antunes Varela (2005, p. 491-493), o ordenamento português comunga das ideias difundidas na literatura jurídica alemã, principalmente pelos doutrinadores do conteúdo de destinação dos direitos absolutos (Zuweisungsgehalt), como se infere no trecho: 
[...] os direitos reais, bem como a propriedade intelectual (direito de autor e propriedade industrial), não constituem simples direitos de exclusão, assentes sobre o dever geral de não ingerência (de terceiros) na ligação do titular com a res, obra, patente, invento, etc. Mais do que isso, os direitos reais e direitos absolutos afins reservam para o respectivo titular o aproveitamento económico dos bens correspondentes, expresso nas vantagens provenientes do seu uso, fruição, consumo ou alienação. Tudo quanto estes bens sejam capazes de render ou produzir pertence, em princípio, de acordo com o conteúdo da destinação ou afectação de tais direitos, ao respectivo titular. A pessoa que, intrometendo-se nos bens jurídicos alheios, consegue uma vantagem patrimonial, obtém-na à custa do titular do respectivo direito, mesmo que este não estivesse disposto a praticar os actos donde a vantagem procede. A aquisição feita pelo intrometido carece de causa, porque, segunda a tal correcta ordenação jurídica dos bens, a vantagem patrimonial alcançada pelo enriquecido pertence a outra pessoa - ao titular do direito.

A jurisprudência do Superior Tribunal de Justiça português, nesse sentido, consolidou que a condictio por intervenção é uma categoria autônoma de enriquecimento sem causa, entendendo que, à luz da teoria do conteúdo da destinação, quando

[...] alguém enriquece através da ingerência em bens alheios, usando-os ou fruindo-os, sem consentimento do seu titular, o "elemento central" do instituto é a obtenção do enriquecimento à custa de outrem, podendo este ocorrer sem que exista dano patrimonial do lesado. (PORTUGAL, 2005)

O reconhecimento da condictio por intervenção trouxe consigo, entretanto, a discussão doutrinária sobre a possibilidade de restituição do lucro da intervenção. É manifesto, no direito português, que na classificação da condictio por intervenção a teoria da ilicitude ou da antijuricidade de Schulz não é aplicada, mas, por outro lado, existem pontuais divergências doutrinárias entre a aplicação da teoria do conteúdo da destinação, segundo os ensinamentos de Wilburg ou de Von Caemmerer. 
Nesse contexto, a divergência está na possibilidade de restituição do lucro da intervenção. A doutrina suscita, essencialmente, o problema da determinação do objeto da restituição: o valor correspondente ao uso, consumo ou fruição do direito violado (concepção clássica de enriquecimento), somados os rendimentos econômicos daí provenientes (lucros da intervenção) (Wilburg) ou apenas o montante correspondente ao uso, consumo ou fruição do direito violado (concepção clássica de enriquecimento) (Von Caemmerer).

Embora as variadas concepções, a maior parte da doutrina, onde se incluem Antunes Varela, Almeida Costa, Rui de Alarcão e Leite de Cam$\operatorname{pos}^{18}$, adota o posicionamento do alemão Wilburg, entendendo que, para além da restituição do enriquecimento em sua concepção clássica, a pretensão ao lucro da intervenção está inserida no âmbito do enriquecimento sem causa e, por isso, deve ser restituída considerando a ligação econômica existente entre os lucros auferidos e os direitos usurpados, consumidos ou empregados.

A esse respeito, Antunes Varela (2005, p. 491-493) dispõe que, embora haja divergência doutrinária, a legislação portuguesa cuidou da problemática ao consagrar, no artigo 479, I, do Código Civil, os limites da obrigação de restituir ${ }^{19}$. Se alguém utilizar abusivamente coisa alheia ou editar obra alheia, assim, deve restituir tudo quanto tenha sido obtido à custa de outrem, os proveitos ou o produto do uso da coisa (lucro da intervenção), e não somente o valor objetivo do uso. Caso contrário, para o autor, "[...] tudo se passaria como se ao intrometido fosse lícito expropriar os bens alheios, alugá-los ou arrendá-los por sua mera força e iniciati-

\footnotetext{
${ }^{18}$ Vieira Gomes também é partidário da hipótese de devolução dos lucros da intervenção ao titular do direito, porém não adere ao posicionamento da doutrina alemã. Para Vieira Gomes (1998, p. 755-756), que o titular do direito não tem apenas o direito de utilizar seus bens, mas também possui uma expectativa legítima de que quando decidir aliená-lo, será nos termos por si escolhidos e "a simples condenação do agente a pagar o preço de mercado faz tabula rasa dessa perda". Ademais, o autor defende a impossibilidade de uma abordagem unitário do tema, defendendo, inclusive, a possibilidade de uma aplicação de uma pena privada (VIEIRA GOMES, 1998, p. 783 e ss.).

${ }^{19}$ Art. 479, I. “A obrigação de restituir fundada no enriquecimento sem causa compreende tudo quanto se tenha obtido à custa do empobrecido ou, se a restituição em espécie não for possível, o valor correspondente".
} 
va, embora pagando o seu justo preço ou a sua justa renda ou aluguel" (ANTUNES VARELA, 2005, p. 491-493).

Corroborando, Leite de Campos (1974, p. 484) disserta que o obtido à custa de outrem é simultaneamente pressuposto e medida da obrigação de restituir, logo, "[...] o enriquecido terá de restituir ao credor aquela parte do enriquecimento que seja imputável economicamente aos bens jurídicos alheios [...]", incluindo os lucros da intervenção.

$\mathrm{O}$ agente interventor, para o autor, deve restituir tudo o que foi obtido à custa de outrem e não somente o valor objetivo do uso, consumo ou fruição. O titular do direito deverá ser restituído também pelos lucros da intervenção, na medida em que estes foram produzidos com os seus bens, não havendo motivos para que o interventor conserve a parcela do acréscimo patrimonial superior ao valor objetivo dos bens utilizados e imputável economicamente a estes (LEITE DE CAMPOS, 1974, p. 489 e 491).

No entanto, doutrinadores como Pereiro Coelho e Menezes Leitão, acabam defendendo a impossibilidade de restituição do lucro da intervenção nos termos do instituto do enriquecimento sem causa, conforme os fundamentos propostos por Von Caemmerer.

Pereira Coelho (1970, p. 84 e 105) conclui que o titular do direito pode exigir do interventor o que este obteve à custa dele, mas só até o limite do valor objetivo do uso ou dos bens comidos ou alienados, não restituindo o lucro da intervenção, pois esta seria a solução que melhor pondera os interesses do interventor e do titular do direito. Na visão do autor, uma vez de boa-fé, o interventor tem direito ao prêmio de sua iniciativa, sendo o lucro da intervenção uma justa contraprestação da atividade desenvolvida, mas, por outro lado, deve pagar ao titular do direito os bens alheios que utilizou, restituindo-lhe o valor objetivo do uso ou consumo do bem (PEREIRA COELHO, 1970, p. 85-88 e 105)20. Uma solução mais

\footnotetext{
${ }^{20}$ Um exemplo de intervenção no patrimônio alheio em que o agente age de boa-fé, reputando tratar-se de direito próprio, é o famoso litígio norte-americano Edwards v. Lee's. Lee's descobriu, em sua propriedade, a entrada de uma caverna que continha numerosas estalactites e estalagmites, bem como um rio subterrâneo. Após a descoberta, converteu a caverna numa atração turística que, posteriormente, justificou a construção de um hotel. Porém, cerca de um terço da gruta estendia-se por uma propriedade limítrofe, as terras
} 
favorável aos interesses do titular do direito, acabaria permitindo a este exigir do interventor todos as vantagens obtidas, acabaria paralisando as atividades e iniciativas das pessoas, que porventura se absteriam de agir se a lei lhes fizesse perder integralmente os frutos de tais atividades e iniciativas. Por outro lado, se o interventor age de má-fé, sabendo que se tratam de bens alheios, a gestão de negócios imprópria seria o princípio hábil à restituição do lucro, permitindo, assim, ao titular do direito a restituição do lucro da intervenção ${ }^{21}$.

Menezes Leitão (2005, p. 880, 881 e 683), aproximando-se da perspectiva de Pereira Coelho, disserta que, uma vez perante a redação do artigo 479 do CC/1966, o objeto da condictio por intervenção é o enriquecimento em sua concepção clássica e não os lucros obtidos através da exploração da propriedade, obra, da marca, da imagem ou do nome do titular do direito. Para o autor, a restituição dos lucros poderá ocorrer, mesmo com a ausência normativa específica, no regime de gestão imprópria de negócios, porém limitados aos casos que restem comprovados o dominus do agente ao encargo inerente ao gestor.

Apesar da ausência de um consenso doutrinário, a construção jurisprudencial portuguesa, por seu turno, vem condenando os interventores a restituir, com fulcro no artigo 479, I, do Código Civil português, o montante que o titular do direito cobraria pela utilização da coisa, da

de Edwards. No caso, não houve ato ilícito, em sentido técnico, da parte do interventor, tampouco danos ao titular do direito, mas este interventor obteve uma vantagem a partir de direito alheio (VIEIRA GOMES, 1998, p. 783).

${ }^{21}$ A gestão de negócios imprópria, em síntese, trata das hipóteses em que falta o animus negotia aliena gerendi, que caracteriza a gestão de negócios propriamente dita. O gestor, sabendo que os bens são alheios, age conscientemente no seu exclusivo interesse, com a intenção de gerir o seu próprio negócio, e não o de outrem, e de fazer seus todos os lucros auferidos a partir da gestão. No entanto, a aplicação do instituto limita-se à gestão de negócios, não sendo ampliada para os demais casos. Ademais, o ordenamento jurídico português não recepcionou a gestão de negócios imprópria, não tendo, inclusive, tradição jurídica nesse sentido. Embora o anteprojeto de Vaz Serra tenha previsto no artigo 717 o regime, o preceito foi eliminado logo na primeira revisão ministerial. O autor sustenta a hipótese por analogia ao artigo 1271 que, como visto anteriormente, diz respeito ao possuidor de má-fé. Os lucros da intervenção seriam restituídos conforme a conexão econômica com os direitos ou bens alheios empregados (PEREIRA COELHO, 1970, p. 105-106 e 109 e ss.). 
imagem, da obra, etc. Ou seja, somente o enriquecimento, e, portanto, se posicionando, como Pereira Coelho e Menezes Leitão, à luz da interpretação restritiva de Von Caemmerer sobre a teoria do conteúdo da destinação, excluindo a pretensão do lucro da intervenção da tutela do instituto do enriquecimento sem causa (PORTUGAL, 2005; PORTUGAL, 2009).

Na última década, porém, a doutrina e a jurisprudência portuguesas acabaram se deparando com a mudança legislativa, promovida pela Lei n. 16/2008, a partir dos ditames da Diretiva 2004/48/CE do Parlamento Europeu e do Conselho, que passou a consagrar os lucros da intervenção como um elemento relevante no cálculo das indenizações, ao lado dos lucros cessantes e dos danos emergentes, como se verá na próxima seção.

\section{O Lucro da Intervenção e a Legislação de Proteção aos Direi- tos de Propriedade Intelectual em Portugal}

Em nível comunitário europeu, a Diretiva 2004/48/CE do Parlamento Europeu e do Conselho, de 29 de abril de 2004, passou a consagrar parâmetros mínimos de proteção aos direitos de propriedade intelectual. Segundo Adelaide Menezes Leitão (2008, p. 175), o objetivo é, assim, “[...] a aproximação das legislações europeias a fim de assegurar um elevado nível de proteção da propriedade intelectual, equivalente e homogéneo, no mercado interno".

A Direita 2004/48/CE procura uma harmonização de aspectos processuais, mas acabou promovendo um alargamento no âmbito do direito material, consagrando um sistema sui generis relativo à obrigação de responsabilidade civil, nos termos do artigo 13:

1. Os Estados-Membros devem assegurar que, a pedido da parte lesada, as autoridades judiciais competentes ordenem ao infrator que, sabendo-o ou tendo motivos razoáveis para o saber, tenha desenvolvido uma atividade ilícita, pague ao titular do direito uma indenização por perdas e danos adequada ao prejuízo por este efetivamente sofrido devido à violação. 
Ao estabelecerem o montante das indenizações por perdas e danos, as autoridades judiciais:

a) Devem ter em conta todos os aspectos relevantes, como as consequências econômicas negativas, nomeadamente os lucros cessantes, sofridas pela parte lesada, quaisquer lucros indevidos obtidos pelo infrator e, se for caso disso, outros elementos para além dos fatores económicos, como os danos extrapatrimoniais causados pela violação ao titular do direito; ou

b) Em alternativa à alínea a), podem, se for caso disso, estabelecer a indenização por perdas e danos como uma quantia fixa, com base em elementos como, no mínimo, o montante das remunerações ou dos direitos que teriam sido auferidos se o infrator tivesse solicitado autorização para utilizar o direito de propriedade intelectual em questão.

2. Quando, sem o saber ou tendo motivos razoáveis para o saber, o infrator tenha desenvolvido uma atividade ilícita, os Estados-Membros podem prever a possibilidade de as autoridades judiciais ordenarem a recuperação dos lucros ou o pagamento das indemnizações por perdas e danos, que podem ser pré-estabelecidos.

A obrigação de indenizar instituída, portanto, embora integre a matriz da teoria geral da responsabilidade civil, tem um alcance mais amplo. Na visão de Adelaide Menezes Leitão (2008, p. 196), a menção legislativa "sabendo-o ou tendo motivos razoáveis para o saber" diz respeito à "atividade ilícita" desenvolvida e, assim,

Não obstante a prevalência do princípio da culpa (verschuldensprinzip), assiste-se, neste aspecto, a uma erosão deste princípio porque a culpa é aferida em relação à ilicitude do acto e não ao resultado que dele provém. É curioso que, neste ponto, haja uma aproximação entre a violação de direitos intelectuais e a violação de normas de protecção, em relação às quais se defende a existência de uma função de Beweiserleichterung, isto é, de facilitação ao lesado da prova do dano, bastando-se com a prova da violação da norma de protecção [...]. 
A conduta do ofensor é reprovável pelo fato de estar em desacordo com o mandamento legal ${ }^{22}$, exigindo um mínimo de diligência para, antes de qualquer utilização comercial ou afins, verificar os registros competentes e se certificar das possibilidades de uso, gozo e fruição do bem imaterial. Caso contrário, o agente ofensor estará sujeito a indenizar o titular do direito em montante adequado aos prejuízos por este sofridos.

A compensação dos prejuízos abrange tanto os danos extrapatrimoniais quanto danos patrimoniais e, conforme aborda Adelaide Menezes Leitão (2008, p. 193), a indenização, neste último caso, segue o princípio da adequação entre dano e indenização, e não o princípio da reparação integral dos prejuízos. A adequação está, pois, concretizada em duas fórmulas distintas: a primeira, correspondente a alínea "a" do número 1, tem em conta, além dos danos emergentes e dos lucros cessantes, os lucros da intervenção e os eventuais danos extrapatrimoniais sofridos pelo lesado; a segunda, trazida na alínea " $b$ " do número 1 , diz respeito a uma quantia fixa e pré-estabelecida, a ser pensada pelos respectivos legisladores nacionais, que deve ser prevista, no mínimo, com base na remuneração de uma licença que permita ao lesante utilizar o direito intelectual violado.

Para Adelaide Menezes Leitão (2008, p. 194; 2010, p. 256),

[...] o legislador comunitário utiliza o instituto da responsabilidade civil de forma a englobar o enriquecimento injusto. Trata-se, neste ponto, de avaliar o lucro da intervenção, isto é, o lucro de ingerência do infractor em bens jurídicos alheios.

A indenização deixa de ser respaldada no dano, como tradicionalmente conhecido, para se localizar entre o dano e o enriquecimento.

${ }^{22}$ A Diretiva tem como orientação: "Quando uma violação tenha sido efectuada sem dolo nem negligência e sempre que as medidas correctivas ou inibitórias previstas napresente directiva sejam desproporcionadas, os Estados-Membros deverão ter a possibilidade de prever a possibilidade de ser atribuída, como medida alternativa, uma compensação pecuniária à parte lesada. Todavia, sempre que a utilização comercial de bens de contrafacção ou a prestação de serviços constituam uma violação de legislação não respeitante à propriedade intelectual ou possam causar danos aos consumidores, tal utilização ou prestação deverá continuar a ser proibida" (Consideração n. 25). 
A justificativa para a solução conferida tem, por fundamento, a adequação aos efetivos prejuízos que o titular do direito de propriedade intelectual possui a partir da intervenção. Além das medidas corretivas, o infrator terá que ressarcir os prejuízos suportados pelo titular do direito que, nesses casos, são de difícil quantificação. Diante da dificuldade, ainda, o legislador optou por facultar aos Estados-Membros a possibilidade de os tribunais ordenarem a recuperação dos lucros ou o pagamento das indenizações por perdas e danos, que podem ser pré-estabelecidos, quando, sem o saber ou não tendo motivos razoáveis para o saber, o infrator tenha desenvolvido uma atividade ilícita (artigo 13, n. 2).

A Diretiva 2004/48/CE rompe, portanto, com a doutrina tradicional da responsabilidade civil, que não se preocupa com as vantagens patrimoniais auferidas pelo lesante, mas sim com a extensão dos danos sofridos pelo lesado. As vantagens patrimoniais indevidamente obtidas por aquele que utiliza ou explora bens de propriedade intelectual, sem autorização, estão aqui consagradas como um critério de cálculo do montante indenizatório, permitindo uma indenização superior aos danos sofridos pela vítima, em sua acepção clássica.

Esse entendimento, por sua vez, a partir das alterações da Lei n. $16 / 2008$, de $1^{\circ}$ de abril de 2008 , responsável por transpor o regime da Diretiva 2004/48/CE, passou a integrar a legislação portuguesas sobre a temática. O artigo 211 do CDADC e no artigo 338-L do CPI passaram a considerar os lucros da intervenção, os lucros cessantes, os danos emergentes sofridos pelo titular do direito e aos encargos suportados com a proteção do direito, bem como com a investigação e cessação da conduta lesiva, ao quantificar os danos patrimoniais (artigo 211, II, e artigo 338L, II) e, ainda, para o cálculo da indenização, à importância resultante da conduta ilícita do infrator (artigo 211, III e artigo 338-L, III) ${ }^{23}$.

\footnotetext{
${ }^{23}$ Art. 211, I. "Quem, com dolo ou mera culpa, viole ilicitamente o direito de autor ou os direitos conexos de outrem, fica obrigado a indemnizar a parte lesada pelas perdas e danos resultantes da violação"; II. "Na determinação do montante da indemnização por perdas e danos, patrimoniais e não patrimoniais, o tribunal deve atender ao lucro obtido pelo infractor, aos lucros cessantes e danos emergentes sofridos pela parte lesada e aos encargos por esta suportados com a protecção do direito de autor ou dos direitos conexos, bem como com a investigação e cessação da conduta lesiva do seu direito"; III. "Para o
} 
A grande problemática está, pois, que, tradicionalmente, no direito português, o lucro da intervenção diz respeito ao instituto do enriquecimento sem causa, e a teoria geral da responsabilidade civil não contempla outros critérios de fixação da indenização, senão o princípio da reparação integral dos prejuízos e a teoria da diferença ${ }^{24}$. O princípio subjacente à obrigação de indenizar é a reconstrução da situação em que o lesado estaria se não houvesse o evento danoso (artigo 562 do Código Civil português), ou seja, a reposição natural e, sendo impossível reconstruir o estado anterior à lesão, passa-se à possibilidade de indenização em pecúnia, considerando a extensão dos danos (RIBEIRO DE ALMEIDA, 2014, p. 169).

As legislações analisadas, outrossim, tal como previsto na Diretiva 2004/48/CE, consagram a possibilidade de, se o lesado a tal não se opuser, ser arbitrada uma quantia fixa com recurso à equidade, que tenha por base, no mínimo, as remunerações que teriam sido auferidas caso o infrator tivesse solicitado autorização para utilizar os direitos em questão e os encargos por aquela suportados com a proteção do seu direito e com a investigação e cessação da sua correspondente conduta lesiva (artigo 211, V e artigo 338-L, V). Além disso, tratando-se de prática reiterada ou gravosa, o legislador facultou aos tribunais a possibilidade de fixar a indenização aplicando, cumulativamente, todos ou alguns critérios referi-

cálculo da indemnização devida à parte lesada, deve atender-se à importância da receita resultante da conduta ilícita do infractor, designadamente do espectáculo ou espectáculos ilicitamente realizados". Art. 338-L, I. "Quem, com dolo ou mera culpa, viole ilicitamente o direito de propriedade industrial de outrem, fica obrigado a indemnizar a parte lesada pelos danos resultantes da violação"; II. "Na determinação do montante da indemnização por perdas e danos, o tribunal deve atender nomeadamente ao lucro obtido pelo infractor e aos danos emergentes e lucros cessantes sofridos pela parte lesada e deverá ter em consideração os encargos suportados com a protecção, investigação e a cessação da conduta lesiva do seu direito"; III. "[...] Para o cálculo da indemnização devida à parte lesada, deve atender-se à importância da receita resultante da conduta ilícita do infractor". ${ }^{24} \mathrm{~A}$ teoria da diferença (Differenzhypothese) é utilizada para avaliar o resultado do evento danoso (dano) no sentido patrimonial, "mediante a apreciação concreta das alterações verificadas no patrimônio do lesado. Para apreciação dessas diferenças efectua-se uma comparação entre a situação patrimonial actual efectiva do lesado e sua situação patrimonial actual hipotética se não existissem danos" (MENEZES LEITÃO, 2018, p. 403-404). 
dos na norma, a saber: os danos não patrimoniais e os danos patrimoniais, incluindo os lucros da intervenção, os lucros cessantes e os danos emergentes, e os encargos suportados com a proteção do direito, como a investigação e cessação da conduta lesiva (artigo 211, VI e artigo 338-L, VI) ${ }^{25}$.

A doutrina portuguesa questiona a inserção dos lucros da intervenção no âmbito da responsabilidade civil e não do enriquecimento sem causa, como tradicionalmente ocorre. A quem defenda, por outro lado, como Paula Lourenço (2010, p. 1.101), que os lucros da intervenção, tal como a Diretiva 2004/48/CE estabelece, devem permanecer na seara da responsabilidade civil, mas não se caracterizam como indenização punitiva, pois a pretensão punitiva não depende da análise dos lucros angariado pelo interventor.

A jurisprudência, após as alterações da Lei n. 16/2008, vem aplicando as disposições do artigo 211 do CDADC e do artigo 338-L do CPI, considerando um caráter corretivo nas indenizações envolvendo os direitos de propriedade intelectual.

Dos fundamentos de uma das decisões do Tribunal da Relação Porto, envolvendo a violação de direitos autorais, extrai-se:

${ }^{25}$ Art. 211, V. "Na impossibilidade de se fixar, nos termos dos números anteriores, o montante do prejuízo efectivamente sofrido pela parte lesada, e desde que este não se oponha, pode o tribunal, em alternativa, estabelecer uma quantia fixa com recurso à equidade, que tenha por base, no mínimo, as remunerações que teriam sido auferidas caso o infractor tivesse solicitado autorização para utilizar os direitos em questão e os encargos por aquela suportados com a protecção do direito de autor ou direitos conexos, bem como com a investigação e cessação da conduta lesiva do seu direito". Art. 338L, V. "Na impossibilidade de se fixar, nos termos dos números anteriores, o montante do prejuízo efectivamente sofrido pela parte lesada, e desde que esta não se oponha, pode o tribunal, em alternativa, estabelecer uma quantia fixa com recurso à equidade, que tenha por base, no mínimo, as remunerações que teriam sido auferidas pela parte lesada caso o infractor tivesse solicitado autorização para utilizar os direitos de propriedade industrial em questão e os encargos suportados com a protecção do direito de propriedade industrial, bem como com a investigação e cessação da conduta lesiva do seu direito". A redação do VI é igual nos artigos: "Quando, em relação à parte lesada, a conduta do infractor constitua prática reiterada ou se revele especialmente gravosa, pode o tribunal determinar a indemnização que lhe é devida com recurso à cumulação de todos ou de alguns dos critérios previstos nos n.os 2 a 5 ". 
Verifica-se, assim, que, presentemente, a indemnização assume uma tríplice vertente ou natureza, a saber: a) ressarcitória, na medida em que pretende tornar indemne danos emergentes, lucros cessantes, danos morais (que sejam considerados provados), b) correctiva, pois que visa remover o lucro ilícito e os benefícios indevidamente obtidos pelo infractor; c) Preventiva e dissuasora já que pretende evitar que, no futuro o infractor reitere a sua actividade ilegal.

Sendo que, não obstante privilegiar a indemnização correspondente ao prejuízo efectivamente sofrido, no caso de não se apurarem factos que o concretizem, nem seja perspectivável que tal se verifique em sede de execução de sentença, sempre será possível, a título subsidiário, arbitrar tal indemnização equitativamente.

Importando ainda notar que para que esta indemnização alternativa possa ter lugar, duas restrições são impostas. O lesado não pode opor-se e o quantum não pode ser inferior às remunerações que teriam sido auferidas caso o infractor tivesse solicitado autorização para utilizar os direitos em questão e os encargos por aquela suportados com a protecção do direito de autor ou dos direitos conexos, bem com a investigação e cessação da conduta lesiva do seu direito.

O que demonstra que a lei considera que o prejuízo real e efectivo seguramente não é inferior a tais valores e, por via de regra, será até superior. Atente-se, enfim, o aspecto preventivo - e, até, sancionatório, no plano do direito civil - que dimana da cumulação indemnizatória permitida pelo $\mathrm{n}^{\circ} 6$ para os casos de prática reiterada ou especialmente gravosa. (PORTUGAL, 2009)

O Superior Tribunal de Justiça português posicionou-se no sentido de que ficando provado que o lesado é titular de um direito de propriedade intelectual, bem como que o lesante usou, sem autorização, um bem imaterial de propriedade daquele, encontram-se preenchidos os requisitos da responsabilidade civil nos quadros estabelecidos pela Lei n. 16/2008 e assim o dever de indenizar. A indenização a ser fixada, em primeiro, deve ter por base os danos ou prejuízos, que podem ser de natureza patrimonial 
ou não patrimonial e abrange danos emergentes, lucros cessantes e os lucros da intervenção (PORTUGAL, 2014) ${ }^{26}$.

Menezes Leitão (2018, p. 301-302), finalmente, entende que os novos critérios de fixação das indenizações no âmbito dos direitos de propriedade intelectual restringem-se aos casos de dolo ou culpa, permanecendo aberta a via da cláusula geral de enriquecimento sem causa às hipóteses de intervenção não culposa do interventor, sendo a restituição correspondentes, nesses casos, ao enriquecimento em sua concepção clássica.

\section{Conclusão}

As principais anotações sobre o lucro da intervenção estão no sentido que a temática é rica e merece especial atenção da civilística nos dias de hoje, bem como fomenta, não só o recente debate nacional, mas também o debate doutrinário e jurisprudencial no direito estrangeiro. Em Portugal, embora a ideia de auferir lucros a partir da intervenção nos direitos subjetivos alheios tenho sido "descoberta" há quase quatro décadas, ainda hoje, não há consenso na doutrina acerca da possibilidade de restituição dos lucros da intervenção.

Do exame proposto, pode-se concluir que o lucro da intervenção é reconhecido como um produto do instituto do enriquecimento sem causa em Portugal, a partir da condictio por intervenção e da teoria do conteúdo da destinação. Todavia, a doutrina diverge sobre o objeto a ser restituído nesta classificação - se todas as vantagens patrimoniais auferidas pelo interventor (enriquecimento e lucro da intervenção), considerando a análise da contribuição dos envolvidos seguindo a doutrina de Wilburg, ou apenas o enriquecimento em sua concepção clássica, como defende Von Caemmerer - e, assim, a possibilidade de restituição dos lucros estaria

\footnotetext{
${ }^{26} \mathrm{O}$ caso tratava-se de violação ao direito autoral. O autor da demanda era titular dos direitos sob um quadro que foi reproduzido e comunicado ao público pela ré sem a sua autorização. Ainda, atendendo à escassez de elementos probatórios, a indenização restou fixada por via de equidade no valor de $€ 20.000$ (vinte mil euros). Vale lembrar que o CC português determina que não sendo possível averiguar "o valor exato dos danos, o tribunal julgará equitativamente dentro dos limites que tiver por provados" (artigo 566, n. 3).
} 
condicionada à adoção da corrente de Wilburg, defendida, entre outros, por Antunes Varela e Leite de Campos. Por outro lado, as decisões do STJ português vêm condenando os interventores a restituir apenas o enriquecimento, excluindo da tutela do instituto do enriquecimento sem causa a restituição do lucro da intervenção.

O legislador português, ademais, considerando as diretivas da comunidade europeia, acabou por consolidar, recentemente, os lucros da intervenção como um critério para quantificação das indenizações, ao tratar de violação aos direitos de propriedade intelectual, o que está sendo seguido pela jurisprudência, mas causando novas divergências doutrinárias.

A expectativa é de que esse artigo, portanto, tenha servido como norte para tão rica temática, que vem recebendo atenção especial da academia brasileira. Após a leitura integral, pode-se dizer, outrossim, que o presente trabalho cumpriu seu objetivo principal, enquanto se logrou traçar as linhas gerais do tratamento conferido ao tema no ordenamento jurídico português, o que, certamente, poderá servir de substrato dogmático para o direito brasileiro.

\section{Referências}

ANTUNES VARELA, João de Matos. Das Obrigações em Geral. 10. ed. Coimbra: Almedina, 2005. v. I.

BASOZABAL ARRUE, Xabier. Enriquecimiento Injustificado por Intromision en Derecho Ajeno. Madri: Editorial Civitas, 1998.

FUJI, Alessandra Hirano. O conceito de lucro econômico no âmbito da contabilidade aplicada. Revista Contabilidade \& Finanças, [s.l.], v. 15, n. 36, p. 74-86, 2004.

KONDER, Carlos Nelson. Dificuldades de uma abordagem unitária do lucro da intervenção. Revista de Direito Civil Contemporâneo, [s.l.], v. 13, Ano 4, p. 231-248, 2017.

LEITE DE CAMPOS, Diego José Paredes. A subsidiariedade da obrigação de restituir o enriquecimento. Coimbra: Almedina, 1974. 
LEITÃO, Adelaide Menezes. A tutela dos direitos de Propriedade Intelectual na Directiva 2004/48/CE. Revista Direito da Sociedade da Informação, Coimbra, v. VII, p. 173-205, 2008.

LEITÃO, Adelaide Menezes. O Reforço da Tutela da Propriedade Intelectual na Economia Digital através de Acções de Responsabilidade Civil. Revista do Direito Industrial, Coimbra, v. VII, p. 239-264, 2010. LOURENÇO, Paula Meira. Os Danos Punitivos. Revista da Faculdade de Direito da Universidade de Lisboa, Coimbra, v. XLIII, n. 2, p. 1.019-1.111, 2010.

MENEZES LEITÃO, Luís Manuel Teles de. Direito de Autor. 2 ed. Coimbra: Almedina, 2018.

MENEZES LEITÃO, Luís Manuel Teles de. O enriquecimento sem causa no direito civil: estudo dogmático sobre a viabilidade da configuração unitária do instituto face à contraposição entre as diferentes categorias de enriquecimento sem causa. Coimbra: Almedina, 2005. MENEZES LEITÃO, Luís Manuel Teles de. O enriquecimento sem causa no novo Código Civil brasileiro. Revista CEJ, Brasília, n. 25, p. 24-33, abr.-jun., 2004.

PEREIRA COELHO, Francisco Manuel. O enriquecimento e o dano. Coimbra: Almedina, 1970.

PETEFFI DA SILVA, Rafael. Antijuridicidade na responsabilidade civil extracontratual: da amplitude conceitual aos mecanismos de identificação. In: BENETTI, Giovana et al. (org.) Direito, cultura, método: leituras da obra de Judith Martins-Costa. 1. ed. Rio de Janeiro: LMJ Mundo Jurídico, 2019, p. 448-523.

PORTUGAL, Superior Tribunal de Justiça. Recurso de Revista n. 2021/04. Relator: Custódio Montes, 24 de fevereiro de 2005. Disponível em: http://www.dgsi.pt/jstj.nsf/954f0ce6ad9dd8b980256b5f003fa814/5b 5d8f2aff1168ae8025700600492300?OpenDocument. Acesso em: 25 set. 2018. 
PORTUGAL, Superior Tribunal de Justiça. Recurso de Revista, Proc. 20/03.3TYLSB.S1, Relator: Moreira Alves, 3 de novembro de 2009. Disponível em: https://www.stj.pt/wp-content/uploads/2018/01/ propriedadeindustrialdireitosautor_2016.pdf. Acesso em: 25 set. 2018. PORTUGAL, Superior Tribunal de Justiça. Recurso de Revista, Proc. 3952/08.9TJVNF.P1.S1, Relatora: Silva Gonçalves, 17 de dezembro de 2014. Disponível em: https://www.stj.pt/wp-content/uploads/2018/01/ propriedadeindustrialdireitosautor_2016.pdf. Acesso em: 25 set. 2018. PORTUGAL, TRP, Apelação, Proc. RP200901270826702, Relator: Carlos Moreira, 27 de janeiro de 2009. Disponível em: http://www.trp. pt/d. Acesso em: 27 set. 2018.

REALE, Miguel. Lições preliminares de direito. 27. ed. 5 tir. São Paulo: Saraiva, 2005.

RIBEIRO DE ALMEIDA, Alberto. Responsabilidade Civil pela violação de Direitos Subjetivos de Propriedade Intelectual - As influências anglosaxónicas. Revista de Direito Intelectual, Coimbra, n. 2, p. 165-187, 2014.

SAVI, Sérgio. Responsabilidade civil e enriquecimento sem causa: o lucro da intervenção. São Paulo: Atlas, 2012.

VIEIRA GOMES, Júlio Manuel. O conceito de enriquecimento, o enriquecimento forçado e os vários paradigmas do enriquecimento sem causa. Porto: UCP, 1998.

VON CAEMMERER, Ernst. Problèmes fondamentaux de l'enrichissement sans cause. Revue internationale de droit comparé, [s.l.], v. 18, n. 3, p. 573-592, jul.-set., 1966.

Sabrina Jiukoski da Silva é doutoranda e mestra em Direito pelo Programa de Pós-Graduação em Direito da Universidade Federal de Santa Catarina (UFSC). Pós-graduada em Direito Processual Civil pela Faculdade Cesusc. Bolsista CNPq e membro do Grupo de Pesquisa de Direito Civil Contemporâneo. 
E-mail: sjiukoski@gmail.com

Endereço profissional: Universidade Federal de Santa Catarina, Centro de Ciências Jurídicas, Trindade, Florianópolis, SC. CEP 88.040-900.

ORCID: https://orcid.org/0000-0003-0495-9422

Rafael Peteffi da Silva é pós-doutor em Direito pela Universidade de Girona (ES). Doutor em Direito Civil pela Universidade de São Paulo (USP). Mestre em Direito pela Universidade Federal do Estado do Rio Grande do Sul (UFRGS). Professor Associado da Universidade Federal de Santa Catarina (UFSC). Coordenador da Rede de Direito Civil Contemporâneo.

E-mail: rpeteffi@gmail.com

Endereço profissional: Universidade Federal de Santa Catarina, Centro de Ciências Jurídicas, Trindade, Florianópolis, SC. CEP 88.040-900.

ORCID: https://orcid.org/0000-0001-6913-9818 